\title{
Characterization of Modified Magnetite Nanoparticles for Albumin Immobilization
}

\author{
A. K. Bordbar, ${ }^{1,2}$ A. A. Rastegari, ${ }^{3}$ R. Amiri, ${ }^{1}$ E. Ranjbakhsh, \\ M. Abbasi, ${ }^{1}$ and A. R. Khosropour ${ }^{1}$ \\ ${ }^{1}$ Department of Chemistry, University of Isfahan, Isfahan 81746-73441, Iran \\ ${ }^{2}$ Department of Biotechnology, Faculty of New Science and Technology, University of Isfahan, Isfahan 81746-73441, Iran \\ ${ }^{3}$ Department of Molecular and Cell Biochemistry, Falavarjan Branch, Islamic Azad University, Isfahan, Iran
}

Correspondence should be addressed to A. K. Bordbar; akbordbar@gmail.com

Received 5 February 2014; Accepted 28 April 2014; Published 22 May 2014

Academic Editor: Manuel Canovas

Copyright (C) 2014 A. K. Bordbar et al. This is an open access article distributed under the Creative Commons Attribution License, which permits unrestricted use, distribution, and reproduction in any medium, provided the original work is properly cited.

Magnetite $\mathrm{Fe}_{3} \mathrm{O}_{4}$ nanoparticles (NPs) were prepared by chemical coprecipitation method. Silica-coated magnetite NPs were prepared by sol-gel reaction, subsequently coated with 3-aminopropyltriethoxysilane (APTES) via silanization reaction, and then were activated with 2,4,6-trichloro-1,3,5-triazine (TCT) and covalently immobilized with bovine serum albumin (BSA). The size and structure of the particles were characterized by transmission electron microscopy (TEM), X-ray powder diffraction (XRD), and dynamic light scattering (DLS) techniques. The immobilization was confirmed by Fourier transform infrared spectroscopy (FT-IR). XRD analysis showed that the binding process has not done any phase change to $\mathrm{Fe}_{3} \mathrm{O}_{4}$. The immobilization time for this process was $4 \mathrm{~h}$ and the amount of immobilized BSA for the initial value of $1.05 \mathrm{mg}$ BSA was about $120 \mathrm{mg} / \mathrm{gr}$ nanoparticles. Also, the influences of three different buffer solutions and ionic strength on covalent immobilization were evaluated.

\section{Introduction}

Magnetite nanoparticles are widely studied for their applications in various areas such as removal of organic and inorganic pollutants $[1,2]$, being contrast agent in magnetic resonance imaging (MRI) [3, 4], RNA and DNA purification [5], purification of antibodies [6], drug delivery [7, 8], and enzyme and protein immobilization [9-11]. Magnetite nanoparticles are produced by different methods. Several common methods include coprecipitation, microemulsion, thermal decomposition, and laser pyrolysis synthesis [12-16], in which, among these methods, coprecipitation is a facile and convenient way to synthesize magnetite nanoparticles.

Protein immobilization has wide application in many areas, such as immunological agglutination tests, biosensors, and bioseparation [17-19]. Isolation, separation, and purification of various types of the proteins and peptides are used in almost all branches of biosciences and biotechnologies. The basic principle of batch magnetic separation is very simple [20]. The immobilization of bovine serum albumin (BSA) or other proteins on magnetite nanoparticles has unique advantages: (1) increased surface area to volume and subsequent increase in the amount of immobilized protein onto carrier, (2) easy separation of the reaction mixture under a magnetic field, and (3) biocompatibility and nontoxicity with superparamagnetic properties. The magnetite nanoparticles (NPs) need to be stabilized in the carrier liquid because they tend to agglomerate. In order to prevent this problem, the $\mathrm{Fe}_{3} \mathrm{O}_{4}$ NPs are coated with a surfactant or a polymer [4, 2124]. At $\mathrm{pH}$ range between 4 and 8 , the surface charge density is low then; it is difficult to break up the agglomerations formed. For serum albumin at the high and low $\mathrm{pH}$ range, $\zeta$-potential shows the highest values; therefore, sonication should be strong enough to break the weak bonding and prevent agglomeration [25].

According to the type of linkage of the protein, the carrier-binding immobilization is classified into three categories (adsorption, ionic, and covalent immobilization). The covalent immobilization can lead to irreversible binding of protein on different carriers. Bovine serum albumin (BSA) 
was covalently immobilized onto magnetite nanoparticles by different agents [26-29]. Human serum albumin was covalently immobilized on modified magnetic NPs so that it is significant for its magnetic applications in various bioprocesses, biomedical devices, and biomedicine [30].

Previously, we studied immobilization of porcine pancreas lipase (PPL) on chemically modified magnetite nanoparticles [31]. In this study, the silica-coated magnetite nanoparticles were synthesized. The silica-coated $\mathrm{Fe}_{3} \mathrm{O}_{4}$ nanoparticles is treated with 3-aminopropyltriethoxysilane (APTES) to yield the amino-functionalized magnetic nanoparticles (AFMNs); then with 2,4,6-trichloro-1,3,5triazine as the coupling agent, BSA could be covalently attached to the surface of AFMNs. The characteristics of nanoparticles were investigated using various techniques. The size and morphology of the particles were characterized by dynamic light scattering (DLS) and transmission electron microscopy (TEM) techniques. Different stages of the synthesis of nanoparticles and immobilization were confirmed by Fourier transform infrared spectroscopy (FTIR); and X-ray powder diffraction (XRD) technique revealed phase of the nanoparticles before and after immobilization. Optimization of immobilization conditions was done; and, also, the effects of different buffers and ionic strength on immobilization were efficiency investigated.

\section{Material and Methods}

2.1. Materials. Bovine serum albumin (BSA) and Coomassie Brilliant Blue G-250 were purchased from Sigma-Aldrich Co. Ferric chloride hexahydrate $\left(\mathrm{FeCl}_{3} \cdot 6 \mathrm{H}_{2} \mathrm{O}\right)$, ferrous chloride tetrahydrate $\left(\mathrm{FeCl}_{2} \cdot 4 \mathrm{H}_{2} \mathrm{O}\right), 3$-(triethoxysilyl)propylamin (APTES), ethanol (96\%), tetraethoxysilane (TEOS), trichlorotriazine (TCT), and thetrahydrofuran (THF) were prepared from Merck. $\mathrm{NaH}_{2} \mathrm{PO}_{4} \cdot 2 \mathrm{H}_{2} \mathrm{O}$, $\mathrm{Na}_{2} \mathrm{HPO}_{4} \cdot 12 \mathrm{H}_{2} \mathrm{O}$, and tris- $\mathrm{HCl}$ were purchased from Merck and used for preparation of phosphate and tris- $\mathrm{HCl}$ buffers at $\mathrm{pH}=7.5$.

2.2. Synthesis of Magnetic Nanoparticles. The magnetite nanoparticles were prepared by chemical coprecipitation of $\mathrm{Fe}^{3+}$ and $\mathrm{Fe}^{2+}$ ions with a molar ratio of $2: 1$ [32]. The iron salts were dissolved in deionized water under nitrogen gas at $60^{\circ} \mathrm{C}$, and then ammonia solution was added with vigorous stirring for 30-40 $\mathrm{min}$. The $\mathrm{pH}$ of the solution kept constant in the range of 8-9 at this stage. After the addition of ammonia solution, the color of the solution was black. The magnetite precipitates were separated and washed several times with deionized water and once with ethanol.

2.3. Preparation of Silica-Coated Magnetite Nanoparticles. Silica-coated $\mathrm{Fe}_{3} \mathrm{O}_{4}$ nanoparticles were prepared by the hydrolysis of TEOS using sol-gel process. For this purpose, $0.145 \mathrm{gr} \mathrm{Fe}_{3} \mathrm{O}_{4}$ was mixed with $40 \mathrm{~mL}$ ethanol. The produced suspension was dispersed under ultrasonification for 10$15 \mathrm{~min}$ in the presence of a constant nitrogen flux. $6 \mathrm{~mL}$ water and $3 \mathrm{~mL}$ ammonium hydroxide solution were added to this suspension at room temperature, followed by the addition of $0.4 \mathrm{~mL}$ TEOS with stirring and the $\mathrm{pH}$ kept constant in the range of 9-10. The mixture was stirred for $5 \mathrm{~h}$ and subsequently, was washed with ethanol and water for several times and dried under vacuum at room temperature. The covalent attachment of BSA is shown in Scheme 1.

2.4. Nanoparticles Surface Modification. For the surface modification of the MNPs with 2,4,6-trichloro-1,3,5-triazine, an adaptation of the Wang and Liu et al. method was used [27]. First the silica surface was functionalized by 3aminopropyltriethoxy silane. The obtained MNPs $(240 \mathrm{mg})$ were treated with APTES $(9 \mathrm{~mL})$ in ethanol $(6 \mathrm{~mL})$ to introduce amino groups to the NPs surface. The mixture reacted at room temperature for $2 \mathrm{~h}$, which was followed by heating at $50^{\circ} \mathrm{C}$ for $1.5 \mathrm{~h}$. These NPs were washed successively with ethanol and THF. The obtained NPs were further reacted with TCT $(750 \mathrm{mg})$ in THF $(15 \mathrm{~mL})$ at room temperature for $3 \mathrm{~h}$ under sonication for prevention of any agglomeration. The obtained NPs were washed with THF, ethanol, and Milli-Q water. Finally, the triazine functionalized MNPs were dried under vacuum at room temperature.

2.5. Albumin Immobilization. $4.0 \mathrm{mg}$ of the triazine functionalized MNPs was dispersed in $500 \mu \mathrm{L}$ of phosphate buffer $(50 \mathrm{mM}, \mathrm{pH}=7.5)$ and $500 \mu \mathrm{L}$ of BSA solution $(1 \mathrm{mg} / \mathrm{mL})$ was added to MNPs. The mixture was shaken at room temperature for 1-8 hours. The amount of BSA immobilized on MNPs was determined using the Bradford method.

2.6. Characterization. Size and morphology of magnetic nanoparticles were determined by transmission electron microscopy (Philips CM 10 HT-100 KV) and dynamic light scattering (PMX 200CS particle Metrix, Germany). X-ray diffraction measurement was recorded with X-ray diffractometer Bruker, D8ADVANCE ((Germany) using $\mathrm{Cu} \mathrm{K} \alpha$ radiation $(\lambda=0.1540 \mathrm{~nm}))$. The FT-IR spectra were recorded by a Fourier transform infrared spectrophotometer (JASCO FT/IR-6300, Japan).

\section{Results}

3.1. Characterization of Nanoparticles. The size and morphology of the nanoparticles were studied by DLS and TEM techniques. The particle distribution bar chart of MNPs shows their quantities as well as the size distribution patterns as in Figure 1(a). The TEM picture of silica-coated magnetite nanoparticles were shown in Figure 1(b). The average particles size was estimated to be $17.5-21 \mathrm{~nm}$.

The analysis of FT-IR spectroscopy confirmed different stages of nanoparticles and the binding of BSA on the surface of magnetite nanoparticles. The modification of magnetite nanoparticles was confirmed by using silica-uncoated nanoparticles because the peaks of TCT overlap with silica. Figure 2 shows the FT-IR spectra of the naked $\mathrm{Fe}_{3} \mathrm{O}_{4}$, APTESmodified and TCT-APTES-modified magnetite nanoparticles.

Figure 3 shows the FT-IR spectra of the modified particles with TCT and BSA-bound nanoparticles. The presence of 




SCHEME 1: Covalent attachment of BSA on modified magnetite nanoparticles.



(a)

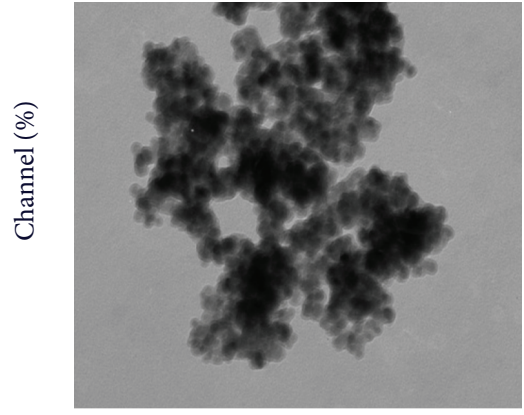

(b)

FIgURE 1: The DLS (a) and TEM (b) of silica-coated MNPs.



FIGURE 2: FT-IR spectra of the naked $\mathrm{Fe}_{3} \mathrm{O}_{4}$, APTES-modified, and TCT-APTES-modified magnetite nanoparticles.

magnetite NPs can be seen by wide strong absorption band between 580 and $630 \mathrm{~cm}^{-1}[33,34]$, especially for $\mathrm{Fe}-\mathrm{O}$ bond of bulk magnetite at $576 \mathrm{~cm}^{-1}$. Also, an absorption band was observed between 400 and $500 \mathrm{~cm}^{-1}$. C-H stretching vibration can be seen at around $2923.5 \mathrm{~cm}^{-1}$. The broad band at $3450 \mathrm{~cm}^{-1}$ can be referred to the $\mathrm{N}-\mathrm{H}$ stretching vibration. The bands around 3430.7 and $1630 \mathrm{~cm}^{-1}$ were assigned to amid group. The fine peaks between 1000 and $1600 \mathrm{~cm}^{-1}$ were assigned to TCT connection to NPs. The bands at 1017.3 and $1030 \mathrm{~cm}^{-1}$ were assigned to the $\mathrm{Si}-\mathrm{O}$ stretching vibration of APTES to the surface of magnetic NPs. Broad peak at 1500 to
TABLE 1: Weight ratio of immobilized BSA to MNPs (mg/g) versus immobilization time BSA on MNPs.

\begin{tabular}{llllll}
\hline $\begin{array}{l}\text { Weight ratio of immobilized BSA } \\
\text { to MNPs (mg/g) }\end{array}$ & 30 & 42 & 40 & 38 & 39 \\
\hline Immobilization time (h) & 2 & 4 & 6 & 7 & 8 \\
\hline
\end{tabular}

$1600 \mathrm{~cm}^{-1}$ were assigned to C-N stretching vibration of BSAMNPs.

The XRD patterns for the modified magnetite NPs without and with bound BSA were recorded in Figure 4. Six characteristic peaks for $\mathrm{Fe}_{3} \mathrm{O}_{4}(2 \theta)$ at $30.06^{\circ}, 35.42^{\circ}, 43.05^{\circ}$, $53.4^{\circ}, 57.15^{\circ}$, and $62.79^{\circ}$ were observed for both samples representing the nonoccurrence of any phase change during the immobilization of BSA.

\subsection{BSA Immobilization Parameters}

3.2.1. Time of Immobilization. The amount of immobilized BSA as a function of reaction time (hour) is shown in Figure 5 and the corresponding data is listed in Table 1. It was found that, with increasing the reaction time from 0 to $4 \mathrm{~h}$ the amount of immobilized BSA increased and then remained constant.

3.2.2. Concentration of Immobilization. In this part, different amounts of the BSA ( 0.3 to $1.462 \mathrm{mg}$ ) were used for immobilization on $4 \mathrm{mg}$ of $\mathrm{Fe}_{3} \mathrm{O}_{4}$ nanoparticles. The amount of 




FIGURE 3: FT-IR spectra of the modified magnetite nanoparticles with (top) and without (bottom) bound BSA.



FIGURE 4: XRD patterns for magnetic nanoparticles with (a) and without (b) BSA.

TABLE 2: Immobilized BSA value on MNPs in different buffers with $\mathrm{pH}=7.5$.

\begin{tabular}{lc}
\hline Various buffers & \% immobilized BSA \\
\hline Tris-HCl & 43.92459 \\
Phosphate buffer saline (PBS) & 43.18039 \\
Phosphate buffer & 49.67127 \\
\hline
\end{tabular}

immobilized BSA increases with increasing the initial value of BSA from 0.3 to $1.0 \mathrm{mg}$ and remains constant after this initial value (see Figure 6). The immobilization time was $4 \mathrm{~h}$ for all measurements.

3.3. Effect of Various Buffer. Different buffers (PBS, tris- $\mathrm{HCl}$, and phosphate buffer) were used to immobilize BSA on magnetite NPs. Table 2 shows the immobilization percentage of protein for these different buffers. The percent of immobilized BSA is not identical for these various buffers with the same $\mathrm{pH}$.

3.4. Effect of Ionic Strength. Figure 7 shows the effect of ionic strength on the immobilized percentage of BSA. Phosphate buffer with different ionic strength (0.1-0.3) was obtained through solving different amounts of sodium chloride salt. Increasing of the ionic strength changes the immobilization percentage of BSA.

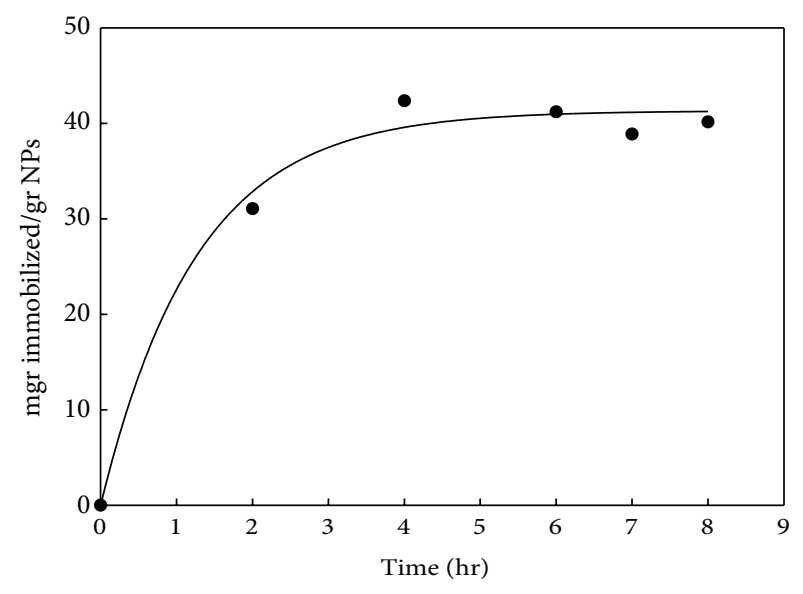

FIGURE 5: Effect of reaction time on the amount of immobilized BSA.



FIgURE 6: Effect of the initial amount of protein on the amount of immobilized BSA.

\section{Discussion}

In the first section of this study, BSA immobilization on magnetite nanoparticles was characterized by TEM, FT-IR, $\mathrm{XRD}$, and DLS techniques. Figure 1(a) shows the particle distribution bar chart of MNPs as well as the size distribution patterns. $132.9 \mathrm{~nm}$ was estimated as the average particle size. The TEM picture of silica-coated magnetite nanoparticles was shown in Figure 1(b). This suggests the achievement of high specific areas of nanoparticles and their spherical shape and granular form.

In Figure 2, a peak at $576 \mathrm{~cm}^{-1}$ is a characteristic peak for $\mathrm{Fe}-\mathrm{O}$ stretching band. The sharp peaks in the range of $1000-1600 \mathrm{~cm}^{-1}$ confirmed binding of TCT on the AFMNPs. After immobilization of BSA on the magnetic nanoparticles, the peaks at $1651.73 \mathrm{~cm}^{-1}$ and $1584.24 \mathrm{~cm}^{-1}$ (see Figure 3) corresponded to the amide $\mathrm{I}$ band $(\mathrm{C}=\mathrm{O}$ stretching vibration) and amide II band ( $\mathrm{N}-\mathrm{H}$ bending vibration and the $\mathrm{C}-\mathrm{N}$ stretching vibration) which reveals that the BSA is immobilized on modified nanoparticles. Therefore, the covalent immobilization of BSA can be concluded from these data.

The XRD pattern in Figure 4 shows that the binding process did not result in the phase change of $\mathrm{Fe}_{3} \mathrm{O}_{4}$. Also, using 




FIGURE 7: Effect of the ionic strength on the immobilization percentage.

Debye-Scherrer equation, the particle size was calculated to be $9-10 \mathrm{~nm}$.

In the second part of this study, some immobilization parameters such as time, concentration of BSA, effect of various buffer, and ionic strength were investigated. The amount of immobilized BSA reached the maximum after $4 \mathrm{~h}$, representing the saturation of nanoparticles with BSA at this time (Figure 5). The weight ratio of immobilized BSA to MNPs at this time was $40 \mathrm{mg} / \mathrm{g}$. According to Figure 6, the amount of immobilized BSA increases with increasing the initial value of BSA and remains constant at about $120 \mathrm{mg} / \mathrm{gr}$ NPs which is in agreement with previous study corresponding to BSA immobilization on coated MNPs with polymer [35]. The extent of immobilization reaches maximum at initial BSA value of $1.05 \mathrm{mg}$ (Figure 6) that is related to saturation of MNPs at this value. This can be easily explained by considering the limited number of active sites on MNPs for attachment of BSA.

The extent of immobilization in phosphate buffer is higher than other examined buffers. This may be related to the deactivation of some active sites on MNPs. The effect of ionic strength on the extent of immobilization is shown in Figure 7. The results represent the decreasing of immobilization due to the increase of ionic strength that can be related to the reduction of electrostatic interactions between BSA and nanoparticles. Similar result has been observed previously [35].

\section{Conclusion}

Silica-coated magnetite nanoparticles were prepared by solgel reaction. The silanization of these coated particles by APTES and their activation by TCT were done, subsequently. BSA was covalently immobilized on these chemically modified MNPs. The size and structure of the particles were investigated by using TEM, XRD, and DLS methods. XRD results showed that the binding process did not induce any phase change on $\mathrm{Fe}_{3} \mathrm{O}_{4}$. Immobilization time for this process was $4 \mathrm{~h}$ and the amount of immobilized BSA was at about $120 \mathrm{mg}$ per gram of nanoparticles. The PBS buffer showed the maximum extent of immobilization among the examined buffers. The obtained results also represent the decreasing of immobilization by increasing the ionic strength. The whole results in this article may be used for biological, biomedical, and biotechnological applications.

\section{Conflict of Interests}

The authors declare that there is no conflict of interests regarding the publication of this paper.

\section{References}

[1] H. Hu, Z. Wang, and L. Pan, "Synthesis of monodisperse $\mathrm{Fe}_{3} \mathrm{O}_{4} @$ silica core-shell microspheres and their application for removal of heavy metal ions from water," Journal of Alloys and Compounds, vol. 492, no. 1-2, pp. 656-661, 2010.

[2] L. Zhou, Z. Liu, J. Liu, and Q. Huang, "Adsorption of $\mathrm{Hg}$ (II) from aqueous solution by ethylenediamine-modified magnetic crosslinking chitosan microspheres," Desalination, vol. 258, no. 1-3, pp. 41-47, 2010.

[3] C. Y. Haw, F. Mohamed, C. H. Chia et al., "Hydrothermal synthesis of magnetite nanoparticles as MRI contrast agents," Ceramics International, vol. 36, no. 4, pp. 1417-1422, 2010.

[4] D. K. Kim, Y. Zhang, J. Kehr, T. Klason, B. Bjelke, and M. Muhammed, "Characterization and MRI study of surfactantcoated superparamagnetic nanoparticles administered into the rat brain," Journal of Magnetism and Magnetic Materials, vol. 225, no. 1-2, pp. 256-261, 2001.

[5] B. Yoza, M. Matsumoto, and T. Matsunaga, "DNA extraction using modified bacterial magnetic particles in the presence of amino silane compound," Journal of Biotechnology, vol. 94, no. 3, pp. 217-224, 2002.

[6] H. Qian, C. Li, Z. Lin, and Y. Zhang, "Using thiophilic magnetic beads in purification of antibodies from human serum," Colloids and Surfaces B: Biointerfaces, vol. 75, no. 1, pp. 342-348, 2010.

[7] S. Guo, D. Li, L. Zhang, J. Li, and E. Wang, "Monodisperse mesoporous superparamagnetic single-crystal magnetite nanoparticles for drug delivery," Biomaterials, vol. 30, no. 10, pp. 1881-1889, 2009.

[8] J. Zhang, S. Rana, R. S. Srivastava, and R. D. K. Misra, "On the chemical synthesis and drug delivery response of folate receptor-activated, polyethylene glycol-functionalized magnetite nanoparticles," Acta Biomaterialia, vol. 4, no. 1, pp. 40-48, 2008.

[9] J. Jordan, C. S. S. R. Kumar, and C. Theegala, "Preparation and characterization of cellulase-bound magnetite nanoparticles," Journal of Molecular Catalysis B: Enzymatic, vol. 68, no. 2, pp. 139-146, 2011.

[10] G. Y. Li, K. L. Huang, Y. R. Jiang, D. L. Yang, and P. Ding, "Preparation and characterization of Saccharomyces cerevisiae alcohol dehydrogenase immobilized on magnetic nanoparticles," International Journal of Biological Macromolecules, vol. 42, no. 5, pp. 405-412, 2008.

[11] F. Šulek, M. Drofenik, M. Habulin, and Ž. Knez, "Surface functionalization of silica-coated magnetic nanoparticles for covalent attachment of cholesterol oxidase," Journal of Magnetism and Magnetic Materials, vol. 322, no. 2, pp. 179-185, 2010.

[12] D. Maity, S.-G. Choo, J. Yi, J. Ding, and J. M. Xue, "Synthesis of magnetite nanoparticles via a solvent-free thermal decomposition route," Journal of Magnetism and Magnetic Materials, vol. 321, no. 9, pp. 1256-1259, 2009. 
[13] I. Martínez-Mera, M. E. Espinosa-Pesqueira, R. PérezHernández, and J. Arenas-Alatorre, "Synthesis of magnetite $\left(\mathrm{Fe}_{3} \mathrm{O}_{4}\right)$ nanoparticles without surfactants at room temperature," Materials Letters, vol. 61, no. 23-24, pp. 44474451, 2007.

[14] R. Strobel and S. E. Pratsinis, "Direct synthesis of maghemite, magnetite and wustite nanoparticles by flame spray pyrolysis," Advanced Powder Technology, vol. 20, no. 2, pp. 190-194, 2009.

[15] S. Sun, H. Zeng, D. B. Robinson et al., "Monodisperse $\mathrm{MFe}_{2} \mathrm{O}_{4}$ $(\mathrm{M}=\mathrm{Fe}, \mathrm{Co}, \mathrm{Mn})$ nanoparticles," Journal of the American Chemical Society, vol. 126, no. 1, pp. 273-279, 2004.

[16] S. C. Tsang, C. H. Yu, X. Gao, and K. Tam, "Silica-encapsulated nanomagnetic particle as a new recoverable biocatalyst carrier," Journal of Physical Chemistry B, vol. 110, no. 34, pp. 16914-16922, 2006.

[17] T. Ahuja, I. A. Mir, and D. Kumar, "Potentiometric urea biosensor based on BSA embedded surface modified polypyrrole film," Sensors and Actuators, B: Chemical, vol. 134, no. 1, pp. 140-145, 2008.

[18] S. Babacan, P. Pivarnik, S. Letcher, and A. G. Rand, "Evaluation of antibody immobilization methods for piezoelectric biosensor application," Biosensors and Bioelectronics, vol. 15, no. 11-12, pp. 615-621, 2000.

[19] K. Yoshinaga, A. Kondo, K. Higashitani, and T. Kito, "Immobilization of protein on monodispersed colloidal silica with poly(ethylene glycol) spacer and application of the composites to immunological agglutination tests," Colloids and Surfaces A: Physicochemical and Engineering Aspects, vol. 77, no. 2, pp. 101107, 1993.

[20] I. Safarik and M. Safarikova, "Magnetic techniques for the isolation and purification of proteins and peptides," BioMagnetic Research and Technology, vol. 2, article 7, 2004.

[21] R. Kaiser and G. Miskolczy, "Magnetic properties of stable dispersions of subdomain magnetite particles," Journal of Applied Physics, vol. 41, no. 3, pp. 1064-1072, 1970.

[22] D. Maity and D. C. Agrawal, "Synthesis of iron oxide nanoparticles under oxidizing environment and their stabilization in aqueous and non-aqueous media," Journal of Magnetism and Magnetic Materials, vol. 308, no. 1, pp. 46-55, 2007.

[23] R. S. Molday and D. Mackenzie, "Immunospecific ferromagnetic iron-dextran reagents for the labeling and magnetic separation of cells," Journal of Immunological Methods, vol. 52, no. 3, pp. 353-367, 1982.

[24] L. Shen, P. E. Laibinis, and T. Alan Hatton, "Bilayer surfactant stabilized magnetic fluids: synthesis and interactions at interfaces," Langmuir, vol. 15, no. 2, pp. 447-453, 1999.

[25] M. Mikhaylova, D. K. Kim, C. C. Berry et al., "BSA immobilization on amine-functionalized superparamagnetic iron oxide nanoparticles," Chemistry of Materials, vol. 16, no. 12, pp. 23442354, 2004.

[26] A.-C. Faure, C. Hoffmann, R. Bazzi et al., "Functionalization of luminescent aminated particles for facile bioconjugation," ACS Nano, vol. 2, no. 11, pp. 2273-2282, 2008.

[27] X. Liu, J. Xing, Y. Guan, G. Shan, and H. Liu, "Synthesis of amino-silane modified superparamagnetic silica supports and their use for protein immobilization," Colloids and Surfaces A: Physicochemical and Engineering Aspects, vol. 238, no. 1-3, pp. 127-131, 2004.

[28] A. Nan, R. Turcu, L. Bratu et al., "Novel magnetic core-shell $\mathrm{Fe}_{3} \mathrm{O}_{4}$ polypyrrole nanoparticles functionalized by peptides or albumin," Arkivoc, vol. 2010, no. 10, pp. 185-198, 2010.
[29] J. T. Chau, G. C. Hong, H. K. Kwee, and W. T. Yen, "Preparation of bovine serum albumin surface-imprinted submicrometer particles with magnetic susceptibility through core-shell miniemulsion polymerization," Analytical Chemistry, vol. 80, no. 3, pp. 683-692, 2008.

[30] K. Can, M. Ozmen, and M. Ersoz, "Immobilization of albumin on aminosilane modified superparamagnetic magnetite nanoparticles and its characterization," Colloids and Surfaces B: Biointerfaces, vol. 71, no. 1, pp. 154-159, 2009.

[31] E. Ranjbakhsh, A. K. Bordbar, M. Abbasi, A. R. Khosropour, and E. Shams, "Enhancement of stability and catalytic activity of immobilized lipase on silica-coated modified magnetite nanoparticles," Chemical Engineering Journal, vol. 179, pp. 272276, 2012.

[32] Y. Wang and B. Liu, "Conjugated polymer as a signal amplifier for novel silica nanoparticle-based fluoroimmunoassay," Biosensors and Bioelectronics, vol. 24, no. 11, pp. 3293-3298, 2009.

[33] R. D. Waldron, "Infrared spectra of ferrites," Physical Review, vol. 99, no. 6, pp. 1727-1735, 1955.

[34] M. Ma, Y. Zhang, W. Yu, H. Y. Shen, H. G. Zhang, and N. Gu, "Preparation and characterization of magnetite nanoparticles coated by amino silane," Colloids and Surfaces A: Physicochemical and Engineering Aspects, vol. 212, no. 2-3, pp. 219-226, 2003.

[35] N. Shamim, L. Hong, K. Hidajat, and M. S. Uddin, "Thermosensitive-polymer-coated magnetic nanoparticles: adsorption and desorption of Bovine Serum Albumin," Journal of Colloid and Interface Science, vol. 304, no. 1, pp. 1-8, 2006. 

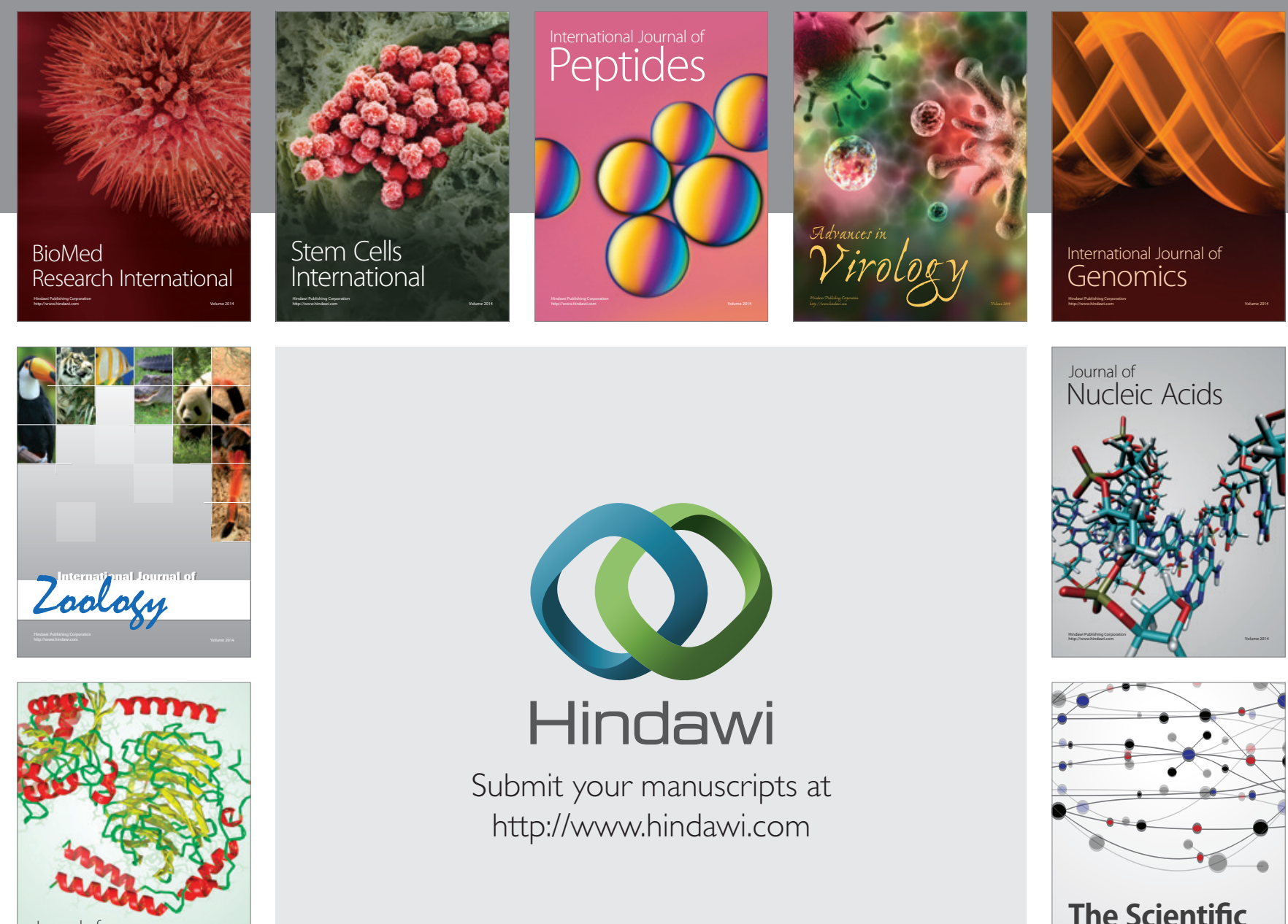

Submit your manuscripts at

http://www.hindawi.com

Journal of
Signal Transduction
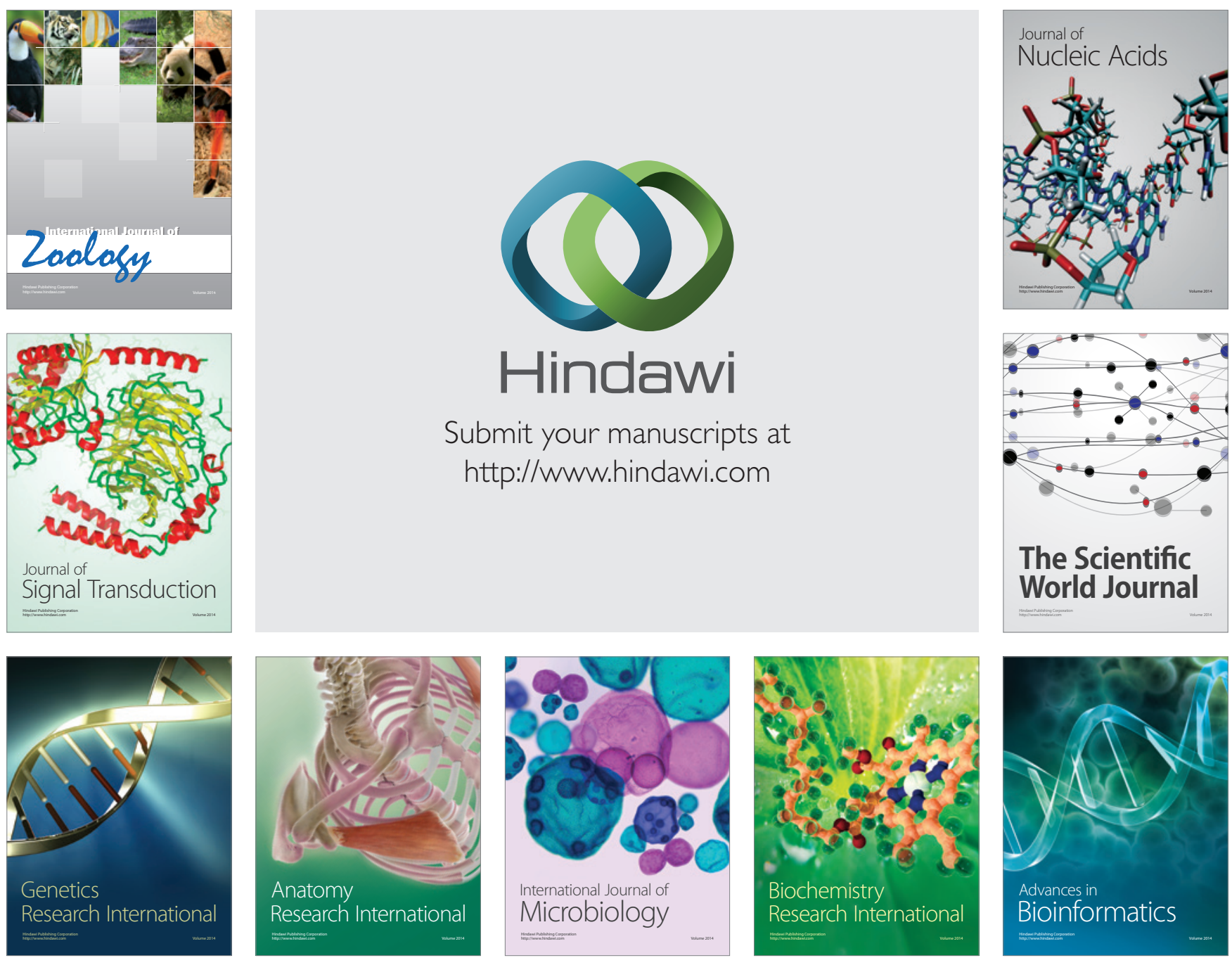

The Scientific World Journal
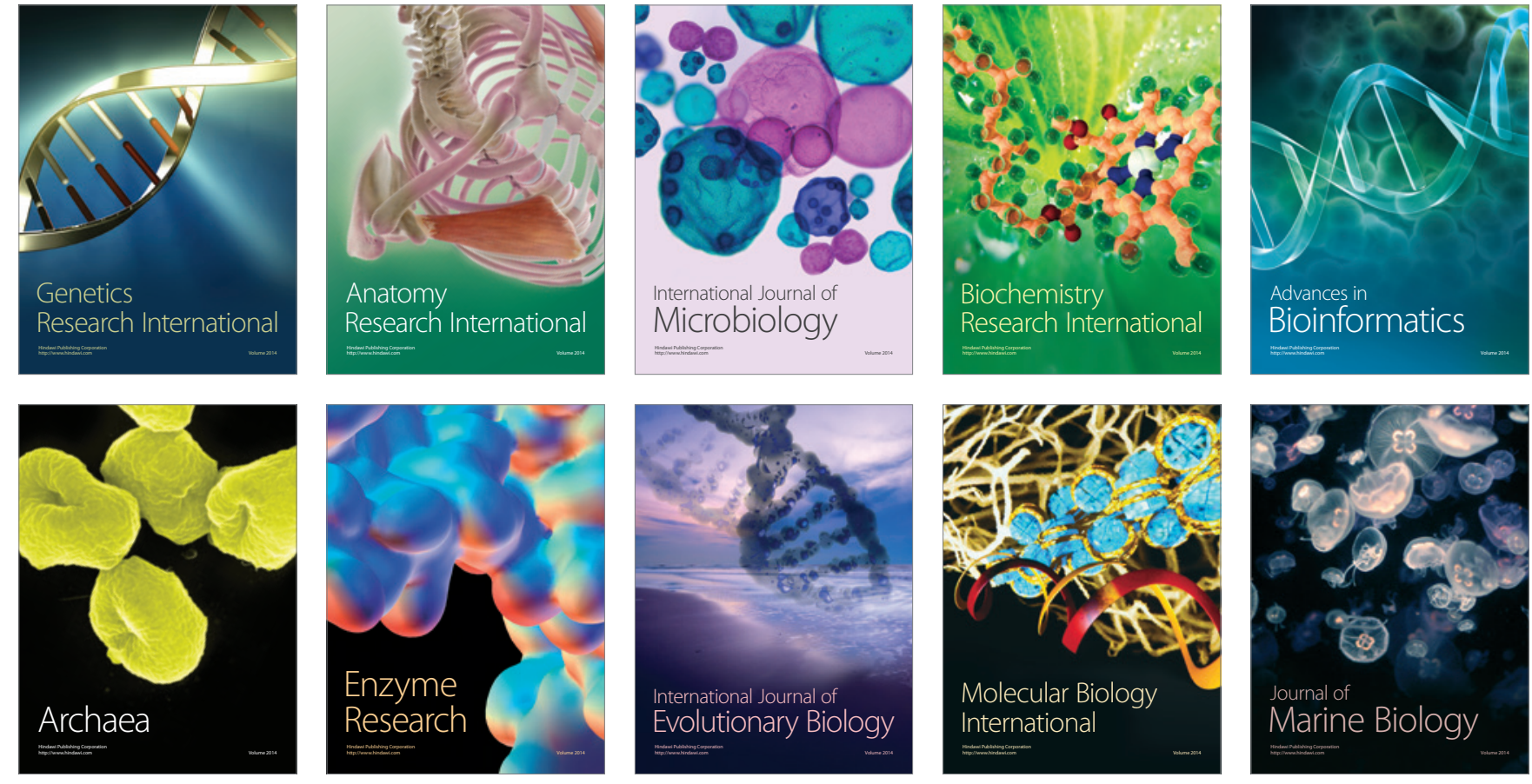